\title{
Separações em colunas abertas: cromatografia por exclusão e por bioafinidade
}

\author{
Carol H. Collins \\ Instituto de Química, Universidade Estadual de Campinas, \\ Cep 13083-970, Campinas, SP, Brasil \\ e-mail:chc@iqm.unicamp.br
}

\section{Resumo}

Na década de 1950, iniciou-se a aplicação de dois outros processos de separação que utilizavam colunas cromatográficas abertas: cromatografia por exclusão e cromatografia por bioafinidade. O desenvolvimento de ambas as técnicas dependeu da comercialização de géis de dextrana e de agarose, altamente porosos, seguida da produção de polímeros orgânicos porosos com propriedades similares. Este capítulo sobre as "Pilares de Cromatografia" descreve o início de ambas as técnicas de separação citadas.

Palavras-chave

História da cromatografia; cromatografia por bioafindade; cromatografia por exclusão por tamanho.

\section{Open column separations: exclusion and bioaffinity chromatographies}

\section{Abstract}

Starting in the 1950s, two other separation processes that use open column chromatography started to be applied: size exclusion and bioaffinity. An important contribution to both these developments involved the commercialization of highly porous dextran and agarose gels, followed soon after by the preparation of porous organic polymers with similar properties. This chapter of "Pillars of Chromatography" describes the early days of both these separation techniques.

Keywords

History of chromatography; bioaffinity chromatography; size exclusion chromatography.

\section{Introdução}

Nos cinquenta anos depois dos primeiros trabalhos de Tswett, nos quais a cromatografia em coluna foi descrita ${ }^{[1]}$, a grande maioria das separações era realizada por cromatografia líquido-sólido em coluna. Em 1940, Martin e
Synge introduziram a cromatografia líquido-líquido em coluna ${ }^{[2]}$. Na década de 1950, duas outras modalidades de cromatografia em coluna foram descritas: a cromatografia por bioafinidade e a cromatografia por exclusão por tamanho. 
A cromatografia por exclusão promove uma distribuição seletiva e dinâmica das moléculas a serem separadas entre dois líquidos, a fase móvel presente dentro dos poros da fase estacionária e a fase móvel externa aos poros. A fase estacionária, insolúvel na fase móvel, é comumente um polímero ou um gel e apresenta poros de tamanhos bem controlados, que regulam a entrada e a saída das moléculas que podem permear parcialmente ou completamente dentro da fase estacionária, sem ter qualquer interação com ela, princípio esse diferente dos mecanismos que governam as outras modalidades de cromatografia. As moléculas que não têm penetração são excluídas e saem primeiro, agrupadas, da coluna, enquanto as que penetram completamente também saem junto no volume total da eluição. Somente as moléculas que penetram parcialmente são separadas (Figura 1).

Esse fenômeno foi notado por vários pesquisadores durante separações realizadas por outros mecanismos. Zeólitos porosos, atuando como peneiras moleculares, foram identificados por McBain em $1926^{[3]}$. Em 1930, Friedman ${ }^{[4]}$ notou que a difusão diferencial da ureia e da glicerina em géis de agar foi inversamente proporcional à concentração da agar no gel. Em 1950, Deuel et al. ${ }^{[5]}$ relataram que diversas separações realizadas em fases estacionárias de diferentes porosidades apresentaram propriedades de peneira, além das interações pretendidas de adsorção ou partição. Uma observação similar foi feita por Wheaton e Bauman ${ }^{[6]}$ em 1953, quando eles descreveram, pela primeira vez, o mecanismo de exclusão por íons, indicando que algumas substâncias não-ionizadas de baixa massa molar foram separadas em resinas de troca iônica, em ordem inversa das suas massas molares. Em 1954, Deuel e Neukom ${ }^{[7]}$ prepararam um gel de um polissacarídeo entrecruzado para uso em desalinização de soluções de macromoléculas. Lindqvist e Storgårds ${ }^{[8]}$, em 1955, utilizaram amido para fracionar peptidos e aminoácidos. Nesses casos, as moléculas maiores passaram rapidamente pela coluna, enquanto os sais penetraram e eluíram bem depois. Nessa época, os processos que aplicavam peneiras moleculares para moléculas pequenas já estavam bem estabelcidos.

Um dos primeiros trabalhos que estudaram com cuidado o processo de peneira para moléculas de tamanho maior foi o de Lathe e Ruthven ${ }^{[9]}$ em 1956 (Figura 2). Esses autores cuidadosamente demonstraram que grãos de amido (de batata ou de milho) contêm poros de tamanhos diferentes, dependendo da quantidade de água (ou tampão) que os incha, e que os diferentes tamanhos de poros permitiram a separação de diversas moléculas, obtendo separações de, por exemplo, globulina e hemoglobina, com massas molares de 150000 e 67000, bem como a separação de carboidratos e compostos similares,
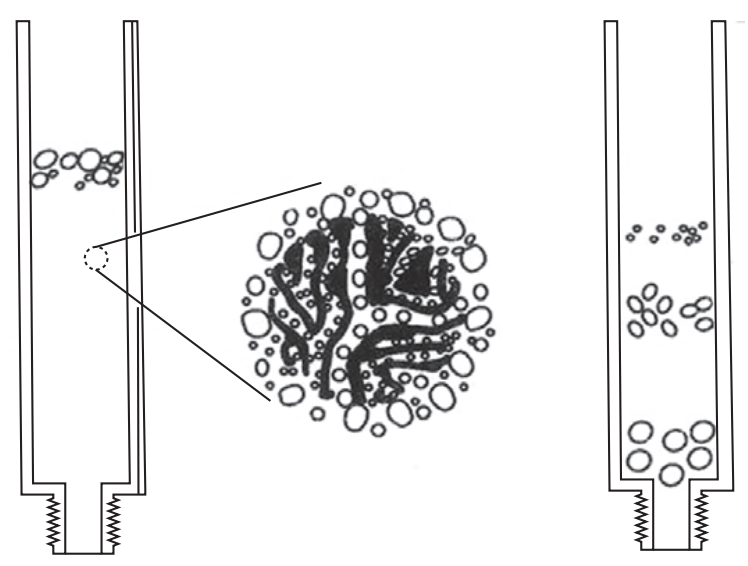

Figura 1 Esquema de uma separação por exclusão por tamanho.

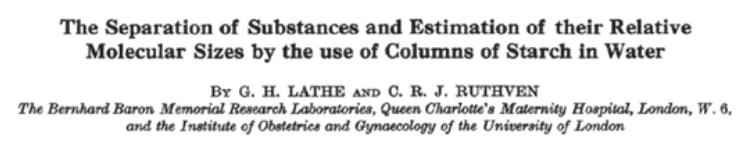

Figura 2 Título do trabalho de Lathe e Ruthven, Biochem. J. 62, 665-674 (1956), descrevendo seus experimentos com peneiras moleculares de amido. 


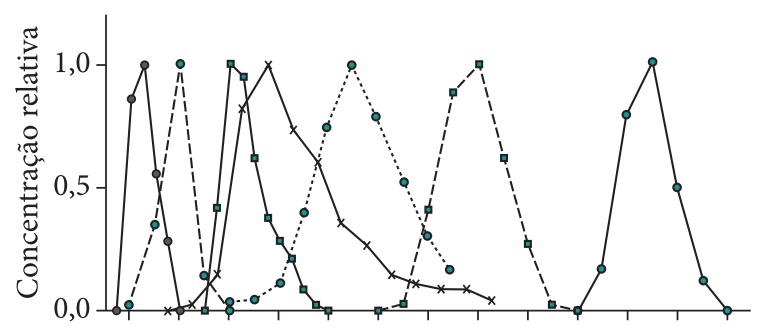

$\begin{array}{lllllllllllll}28 & 30 & 32 & 34 & 36 & 38 & 40 & 42 & 44 & 46 & 48 & 50 & 52\end{array}$

Volume de eluato $(\mathrm{mL})$

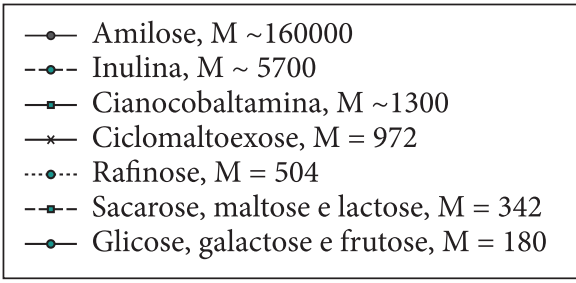

Figura 3 Eluição, separadamente, de diversos compostos neutros de massas molares diferentes, descrita por Lathe e Ruthven ${ }^{[9]}$. A coluna, com diâmetro interno de $16 \mathrm{~mm}$, continha $75 \mathrm{~g}$ de amido de batata em água, e a fase móvel também foi água. Ureia, marcando o volume total da fase móvel, eluiu com 73,5 mL (modificado da referência 9).

com massas molares entre 3000 e 180 (Figura 3). Eles estenderam o estudo para diveras moléculas neutras com massas entre 100 e 400, variando o pH e o tampão, também obtendo separções. Os autores interpretaram seus resultados indicando que moléculas de massas altas não penetraram nos poros do amido e foram eluídas junto com o volume da fase móvel que circula fora dos poros e que moléculas muito pequenas, tais como ureia, penetraram em todos os poros. Os diferentes volumes de retenção das diversas moléculas com massas intermediárias refletem nas penetrações parciais dessas espécies. Esse mecanismo ainda hoje é aceito.

$\mathrm{O}$ uso de amido como fase estacionária apresentou problemas de repetibilidade devido às diferentes fontes de amido e aos diferentes tamanhos dos grãos e como eles inchavam. Tal problema também foi notado pelo grupo do Professor Arne Tiselius, Prêmio Nobel em 1948, na Universidade de Uppsala, na Suécia, o qual tentou utilizar colunas de amido para separações eletroforéticas. Os pesquisadores atribuíram esse efeito às separações relacionadas à penetração diferencial das moléculas no suporte ${ }^{[10]}$. Na tentativa de ter um suporte melhor, eles experimentaram a celulose, com sucesso moderado.

Após defender a sua tese de doutorado em 1954, um dos pesquisadores, Per Flodin, saiu da universidade para trabalhar na firma Pharmacia $\mathrm{AB}$, também em Uppsala. Lá, ele preparou um novo derivado de dextrana entrecruzada com epicloroidrina. Nessa época, a firma Pharmacia vendeu soluções contendo dextranas de diferentes massas molares para serem empregadas em trabalhos clínicos, e a dextrana entrecruzada apresentou massas molares maiores. Flodin deu um bloco dessa dextrana entrecruzada para seu colaborador na universidade, Jerker Porath, que o triturou e peneirou o pó para utilizar em seus experimentos com eletroforese em coluna. Observou o mesmo fenômeno que os dois tinham observado em seus experimentos com amido, a separação por massa molar. Por outro lado, as propriedades dessas partículas de dextrana entrecruzada foram mais reprodutíveis que o amido, e os dois pesquisadores verificaram que esse novo produto poderia ser aplicado em separações baseadas nesse fenômeno.

Em 1958, a firma Pharmacia solicitou várias patentes sobre o produto e o processo de separação ${ }^{[11,12]}$ e, em 1959, iniciou a comercialização de Sephadex". O nome é composto de "Se" de separação, "ph" da firma Pharmacia e "dex" de dextrana. Os primeiros géis comercializados foram preparados por meio de entrecruzamento de dextrana com epicloroidrina e obtidos em forma de blocos que foram subsequentemente triturados e peneirados, apresentando faixas de separação de 1000 a 5000 e de 1500 a 30000 para peptídeos e algumas proteínas ou de 100 a 5000 e de 500 a 10000 para polissacarídeos. 
Paralelamente à comercialização, Porath e Flodin publicaram uma descrição desse processo de separação na revista Nature ${ }^{[13]}$, utilizando, pela primeira vez, o nome "filtração em gel" (Figura 4), sugerido pelo Prof. Tiselius. Eles ilustraram a descrição do processo com uma separação de glicose e duas frações das soluções de dextrana (Figura 5). Nos meses seguintes, Porath e seus alunos publicaram mais seis trabalhos relatando diversas separações, entre elas, de enzimas e hormônios ${ }^{[14]}$.

Todas as separações realizadas por "filtração em gel" utilizaram soluções aquosas, permitindo a separação de um grande número de biomoléculas. Por outro lado, a maioria de polímeros não é solúvel em água, somente em solventes orgânicos, solventes incompatíveis com os géis de Sephadex. Na tentativa de resolver esse problema, em 1960, Vaughan ${ }^{[15]}$ separou poliestirenos de baixa massa molar utilizando pérolas de poliestireno com baixo entrecruzamento, inchadas com benzeno e, em 1961, Cortis-Jones ${ }^{[16]}$ relatou a separação, por massa molar, de algumas moléculas relativamente pequenas, também utilizando colunas de poliestireno entrecruzado. Entretanto, estes poliestirenos não foram úteis para separar macromoléculas, uma vez que os seus poros não possuíam diâmetros apropriados.

Tal problema foi resolvido por John C. Moore, um pesquisador da firma Dow Chemical Company, quando preparou poliestirenos entrecruzados com divinilbenzeno na presença de diversos diluentes, obtendo materiais com maiores diâmetros de poro e permeabilidades em diferentes faixas de 1000 a 250000 em massa molar. Esses resultados foram publicados em 1964 (Figura 6) ${ }^{[17]}$, quando Moore propôs o nome "permeação em gel” para este processo que utilizou solventes orgânicos como fases móveis. A Figura 7 mostra a separação de alguns poliestirenos preparados pela firma Dow Chemical.

\section{GEL FILTRATION: A METHOD FOR DESALTING AND GROUP SEPARATION \\ BY DR. JERKER PORATH \\ Institute of Biochemistry, \\ University of Uppsala \\ AND \\ Dr. PER FLODIN \\ Research Laboratories, Pharmacia, \\ Uppsala}

Figura 4 Título do trabalho de Porath e Flodin, Nature 183, 1657-1659 (1959), descrevendo a filtração em gel.

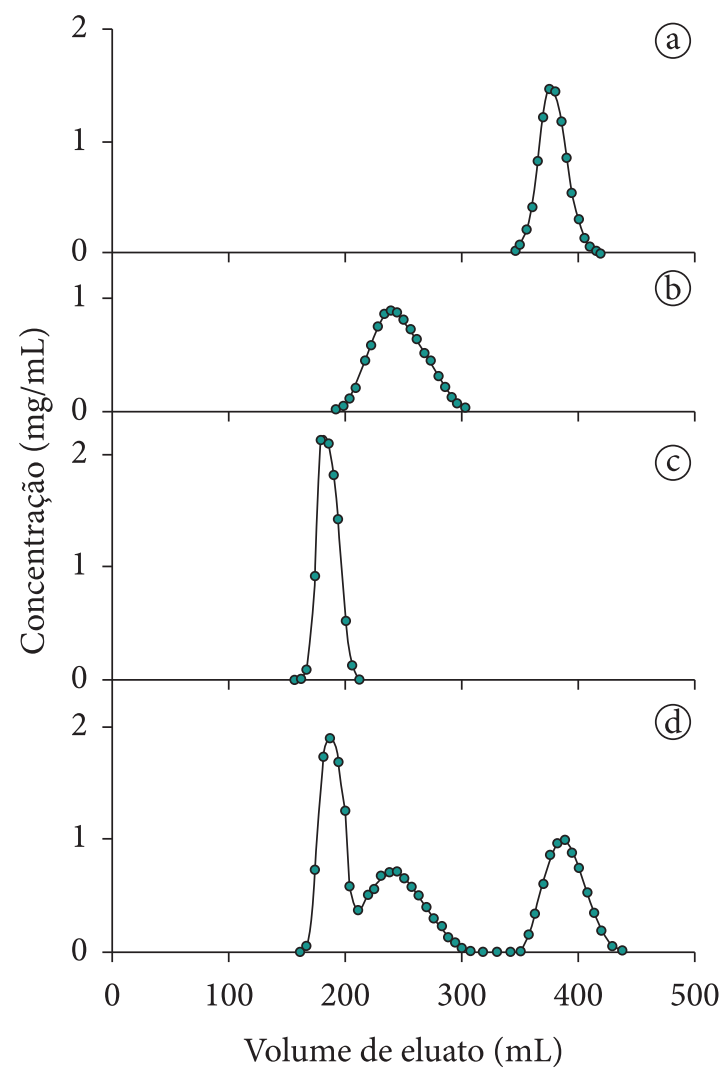

Figura 5 Separação em Sephadex G50, ilustrando a filtração em gel, descrita por Porath e Flodin ${ }^{[13]}$. Fase estacionária: Sephadex G50 (dextrana entrecruzada com epicloroidrina); fase móvel: água. a) Glicose; b) dextrano de $M_{n} 1000$; c) dextrano de $M_{n} 20000$; e d) a mistura dos três soluções (modificada da referência 14).

A distinção entre filtração em gel, que utilizou fases móveis aquosas, e permeação em gel, que utilizou como fases móveis solventes orgâ- 
nicos imiscíveis em água, entre outros nomes empregados para separações baseadas somente na permeação/exclusão dos materiais que estavam sendo separados, foi mantida por mui-

\section{Gel Permeation Chromatography. I. A New Method for Molecular Weight Distribution of High Polymers}

J. C. MOORE, Texas Basic Rescarch Department, The Dow Chemical Company, Freeporl, Tesas

Figura 6 Título do trabalho publicado por J. C. Moore, J. Polym. Sci.: Part A, 2, 835-843 (1964), descrevendo a permeação em gel.

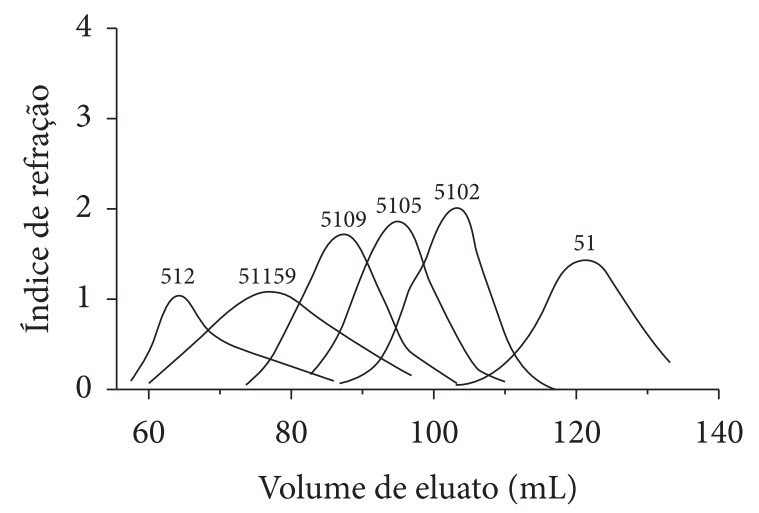

Figura 7 Eluição, separadamente, de vários poliestirenos apresentando massas molares entre 1 milhão (S12) e 14000 (S1) por permeação em gel, descrita por Moore ${ }^{[17]}$. A coluna tinha dimensões de $360 \mathrm{~cm} \times 8 \mathrm{~mm}$, a fase móvel foi tolveno, e a fase estacionária foi um poliestireno entrecruzado com divinilbenzeno na presença de tolueno e $\mathrm{n}$-dodecano, cujo limite de permeabilidade foi $3 \times 10^{5}$ (modificada da referência 17). tos anos, sendo esses nomes substituídos por exclusão por tamanho (size exclusion) no fim do século 20, quando os poliestirenos entrecruzados com divinilbenzeno, mais rígidos, começaram a ser utilizados com fases móveis aquosas ${ }^{[18]}$.

A cromatografia por bioafinidade se distingue das outras modalidades de cromatografia por se basear principalmente nas propriedades biológicas ou funcionais da fase estacionária e da substância (ou substâncias) a ser(em) separada(s) em escala analítica ou semipreparativa (Figura 8). A mistura a ser separada é aplicada no topo de uma coluna que contém um suporte inerte, ao qual um ligante que pode interagir especificamente com a substância desejada está ligado. Uma fase móvel, na qual a interação substância-ligante é favorecida, passa pela coluna até que os componentes da mistura não retida saiam dela. Uma mudança nas propriedades da fase móvel, como mudança no $\mathrm{pH}$ ou na concentração de tampão ou a presença de um deslocador, permite que a substância retida seja eluída.

O primeiro trabalho que descrevia esse processo foi publicado em 1951 por Lerman et al. ${ }^{[20]}$ e abordou o isolamento de um anticorpo utilizando seu antígeno complementar quimicamente ligado à celulose em pó. A celulose purificada foi derivatizada com cloreto de $p$-nitrobenzila, o grupo nitro foi reduzido a uma amina que (a)

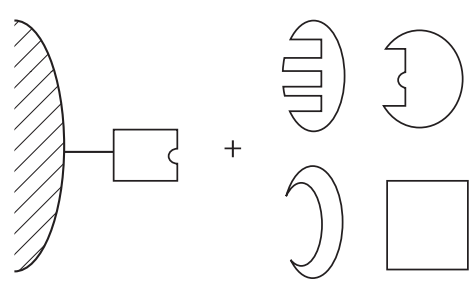

(b)

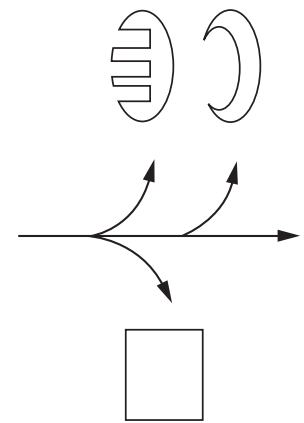

(c)

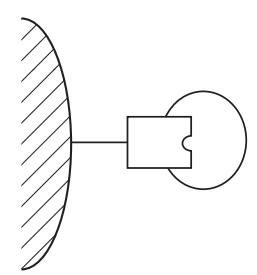

(b)
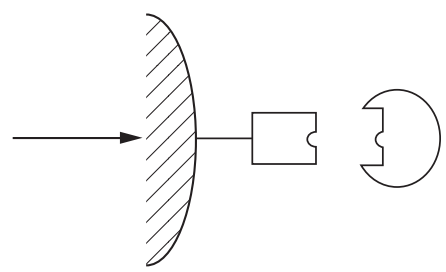

Figura 8 Esquema de uma separação seletiva por bioafinidade. a) Ligante imobilizado; b) mistura a ser separada; c) componente desejado retido pelo ligante imobilizado; e d) elvição do componente retido (modificada da referência 19). 
foi diazotizada e acoplada à albumina bovina, a proteína selecionada, em solução tamponada a pH 8,75 com borato. Os grupos diazo que não reagiram com a proteína foram bloqueados por reação com $\beta$-naftol. O complexo celulose-albumina foi muito estável e um adsorvente eficiente em contato com o soro. Os autores indicaram que inicialmente somente colocaram o soro em contato com o adsorvente e, após certo tempo, separaram o sólido por filtração para eluir os anticorpos retidos. Entretanto, o processo foi muito mais eficiente quando o adsorvente foi colocado em uma coluna cromatográfica, facilitando a remoção dos compostos não retidos. A eluição dos anticorpos desejados foi realizada por modificação do $\mathrm{pH}$ para 3,2. Os autores concluíram que o processo constituía em um novo método para a obtenção de anticorpos com diferentes capacidades de reação. Entretanto, mais de uma década se passou antes que outros pesquisadores aproveitassem tais observações.

Em 1967, Porath et al. ${ }^{[21,22]}$ descreveram a preparação de um gel de agarose ativado com brometo de cianogênio. Agarose é um dextrano entrecruzado com uma estrutura altamente porosa, conhecida pelo nome comercial de Sepaharose, comercializado pela firma sueca Pharmacia ${ }^{[23]}$. Essa agarose ativada por $\mathrm{CNBr}$ pode reagir covalentemente em $\mathrm{pH}$ 10-11, com os grupos aminos primários não-protonados presentes em diversos compostos. O uso de brometo de cianogênio eliminou a necessidade de inativar grupos diazo do método anterior, sendo que a agarose apresenta somente grupos hidroxilas pouco ativos na maioria das situações.

Em 1968, Anfinsen et al. ${ }^{[2]}$ realizaram esse processo para a purificação semipreparativa de diversas enzimas, utilizando colunas cromatográficas (Figura 9). Um dos compostos selecionados para acoplar à Sepharose ativada por $\mathrm{CNBr}$ foi 3' -(4-amino-fenil-fosforil)-

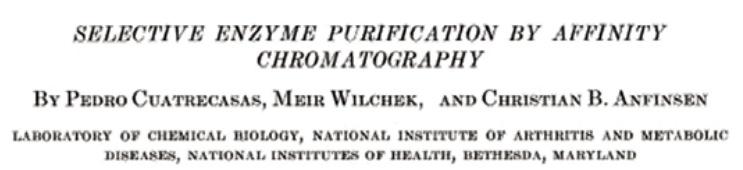

Figura 9 Título do trabalho publicado por Anfinson et al., Proc. Natl. Acad. Sci. U.S.A. 61, 636-643 (1968), considerado o início da cromatografia por bioafinifidade.

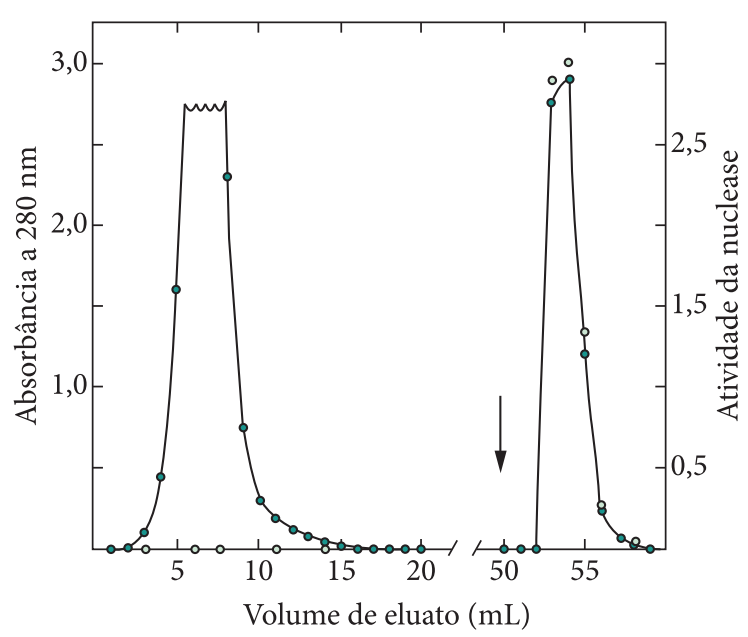

- Absorbância a $280 \mathrm{~nm}$ • Atividade da nuclease

Figura 10 Purificação da nuclease de staphylococcus por cromatografia por bioafinidade. A flecha indica quando a fase móvel foi trocada (modificado da referência 24).

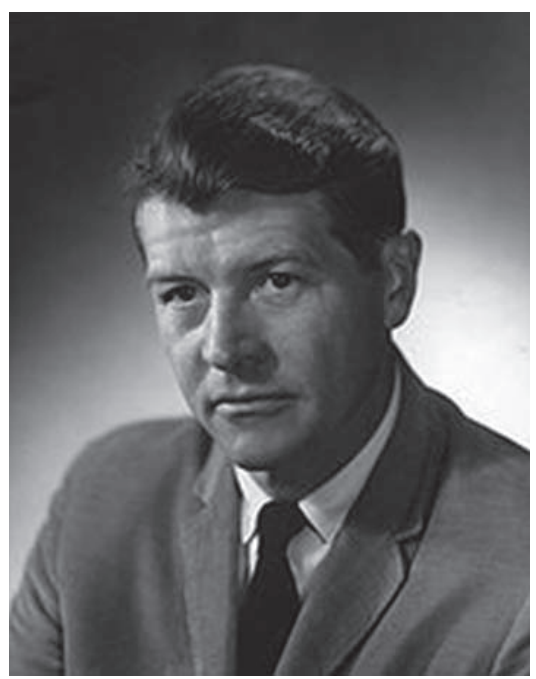

Figura 11 Christian Boehmer Anfinsen (March 26, 1916 - May 14, 1995). 
deoxitimidina-5'-fosfato, e a enzima a ser separada foi a nuclease de staphylococcus. O resultado, purificação completa em uma etapa, é mostrado na Figura 10. A purificação da nuclease de staphylococcus por cromatografia por bioafinidade utilizou uma coluna $(5 \mathrm{~cm} \times 8 \mathrm{~mm})$ de Sepharose especificamente modificada. Antes da aplicação da amostra, a coluna foi equilibrada com tampão borato, 0,05 mol.L $\mathrm{L}^{-1}$, a pH 8 contendo $\mathrm{CaCl}_{2}, 0,01$ mol.L $\mathrm{L}^{-1}$. A amostra (40 mg, contendo $\sim 8 \mathrm{mg}$ de nuclease) foi aplicada em 3,2 mL do mesmo tampão. Após a passagem de $50 \mathrm{~mL}$ do tampão, que eluíram o primeiro pico, a fase móvel foi trocada para ácido acético $0,1 \mathrm{~mol} . \mathrm{L}^{-1}$, eluindo a nuclease, que foi recuperada quantativamente. Frações foram coletadas e seus conteúdos determinados espectrofotometricamente. Os círculos cheios no cromatograma (pico à esquerda) indicam as diferentes substâncias presentes na amostra, as quais não foram retidas pelo grupo quimicamente ligado ao suporte, enquanto o pico após $50 \mathrm{~mL}$ (círculos vazios) indica a nuclease. No mesmo trabalho, os autores também descreveram dois outros pares de composto específico ligado à Sepharose, com a enzima correspondente purificada ${ }^{[24]}$. Este trabalho de purificação de enzimas, entre outros publicados por Christian B. Anfinsen (Figura 11), resultaram no Prêmio Nobel que ele recebeu (dividido com Stein e Moore) em 1972.

\section{Referências}

1. Collins CH. Michael Tswett e o "nascimento" da cromatografia. Scientia Chromatographica 2009; $1(1): 1-21$.

2. Collins $\mathrm{CH}$. Os primordiais da cromatografia líquidolíquido. Scientia Chromatographica 2009; 1(3):7-10.

3. McBain JW. Die Hauptprinzipien der Kolloidchemie. Kolloid Zeitschrift 1926; 40(1):1-9. http://dx.doi. org/10.1007/BF01422275
4. Friedman L. Structure of Agar gels from studies of diffusion. Journal of the American Chemical Society 1930; 52(4):1311-1314. http://dx.doi.org/10.1021/ ja01367a003

5. Deuel H, Solms J, Anyas-Weisz L. Über das Verhalten lösslicher Polyelektrolyte gegenüber Ionenaustauschern. Helvitica Chimica Acta 1950; 33(7):2171-2178. http:// dx.doi.org/10.1002/hlca.19500330722

6. Wheaton RM, Bauman WC. Ion exclusion. A unit operation utilizing ion exchange materials. Industrial and Engineering Chemistry 1953; 45(1):228-233. http://dx.doi.org/10.1021/ie50517a067

7. Deuel H, Neukom H. Some properties of locust bean gum. In Natural Plant Hydrocolloids. Washington: American Chemical Society Advances in Chemistry Series; 1954. p. 51-61. (Advanced Chemistry Series, n. 11).

8. Lindqvist B, Storgårds T. Molecular-sieving properties of starch. Nature 1955; 175:511-512. http://dx.doi. org/10.1038/175511a0

9. Lathe GH, Ruthven CRJ. The separation of substances and estimation of their relative molecular sizes by the use of columns of starch in water. Biochemical Journal 1956; 62(4):665-674.

10. Flodin P, Porath J. Elution and displacement analysis of insulin and adrenocorticotropic peptides on pretreated carbon. Biochimica Biophysica Acta 1954; 13:175-182. http://dx.doi.org/10.1016/00063002(54)90301-7

11. Flodin P, Porath J. Separating substances with different molecular sizes. BRITAIN 865265; 1961.

12. Flodin P, Porath J. Separating substances with different molecular sizes. US Patent 3002 823; 1961.

13. Porath, J, Flodin, P. Gel filtration. A method for desalting and group separation. Nature 1959; 183:1657- 1659. http://dx.doi.org/10.1038/1831657a0

14. Janson J-C. On the history of the development of Sephadex. Chromatographia 1987; 23(5):361-365. http://dx.doi.org/10.1007/BF02316183

15. Vaughan MF. Fractionation of polystyrene by gel filtration. Nature 1960; 188:55. http://dx.doi. org/10.1038/188055a0

16. Cortis-Jones B. 'Gel filtration' of organic compounds. Nature 1961; 191:272-273. http://dx.doi. org/10.1038/191272a0 
17. Moore JC. Gel permeation chromatography. I. A new method for molecular weight distribution of high polymers. Journal of Polymer Science: Part A. 1964; 2:835-843.

18. Anderson DMW, Dea ICM, Hendrie A. Analytical and experimental aspects of molecular-sieve chromatography. Talanta 1971; 18(4):365-394. http:// dx.doi.org/10.1016/0039-9140(71)80056-5

19. Poole CF. The Essence of Chromatography. Amsterdam: Elsevier; 2003. 879 p.

20. Campbell DH, Luescher E, Lerman LS. Immunologic adsorbents. I. Isolation of antibody by means of a cellulose-protein antigen. Proceedings of the National Academy of Sciences of the United States of America 1951; 37:575-578. http://dx.doi.org/10.1073/ pnas.37.9.575
21. Axen R, Porath J, Ernbach S. Chemical coupling of peptides and proteins to polysaccharides by means of cyanogen halides. Nature 1967; 214:1302-1304. http:// dx.doi.org/10.1038/2141302a0

22. Porath J, Axen R, Ernbach S. Chemical coupling of proteins to agarose. Nature 1967; 215:1491-1492. http://dx.doi.org/10.1038/2151491a0

23. Hjertén S. The preparation of agarose spheres for chromatography of molecules and particles. Biochimica et Biophysica Acta 1964; 79(2):393-398. http://dx.doi.org/10.1016/0926-6577(64)90020-8

24. Cuatrecasas P, Wilchek M, Anfinson CB. Selective enzyme purification by affinity chromatography. Proceedings of the National Academy of Sciences of the United States of America 1968; 61(2):636-643. http:// dx.doi.org/10.1073/pnas.61.2.636 